\title{
An empirical model for educational simulation of cervical dilation in first-stage labor
}

\author{
Silvano R. Gefferie ${ }^{1 \dagger}$, Anouk W. J. Scholten ${ }^{1 \dagger}$, Kim A. E. Wijlens ${ }^{1 * \dagger}$ D, M. Luísa Ferreira Bastos ${ }^{2}$, \\ M. Beatrijs van der Hout-van der Jagt ${ }^{3}$, Hans Zwart ${ }^{4}$ and Willem J. van Meurs ${ }^{5}$
}

\begin{abstract}
Background: Several models for educational simulation of labor and delivery were published in the literature and incorporated into a commercially available training simulator (CAE Healthcare Lucina). However, the engine of this simulator does not include a model for the clinically relevant indicators: uterine contraction amplitude and frequency, and cervical dilation. In this paper, such a model is presented for the primigravida in normal labor.

Methods: The conceptual and mathematical models represent oxytocin release by the hypothalamus, oxytocin pharmacokinetics, and oxytocin effect on uterine contractions, cervical dilation, and (positive) feedback from cervical dilation to oxytocin release by the hypothalamus.

Results: Simulation results for cervical dilation are presented, together with target data for a normal primigravida. Corresponding oxytocin concentrations and amplitude and frequency of uterine contractions are also presented.

Conclusion: An original empirical model for educational simulation of oxytocin concentration, uterine contractions, and cervical dilation in first-stage labor is presented. Simulation results for cervical dilation match target data for a normal patient. The model forms a basis for taking into account more independent variables and patient profiles and can thereby considerably expand the range of training scenarios that can be simulated.
\end{abstract}

Keywords: Model, First stage labor, Oxytocin, Uterine contractions, Cervical dilation, Educational simulation

\section{Introduction}

Uterine contractions, fetal descent, and cervical dilation are used to assess progression of labor. These related phenomena vary greatly among parturients and may have an incidence on the condition of the fetus. Simulators allow for practice of normal and critical situations at will and at no risk to real patients. Several models for educational simulation of labor and delivery were published in the literature [1-3] and incorporated into a commercially available training simulator [4]. The cited models make amplitude, frequency, duration, and resting tone of the uterine pressure waveform evolve spontaneously and under the influence of

\footnotetext{
* Correspondence: k.a.e.wijlens@student.utwente.nl

†'Silvano R. Gefferie, Anouk W. J. Scholten and Kim A. E. Wijlens contributed equally to this work.

${ }^{1}$ Technical Medicine, University of Twente, Drienerlolaan 5, 7522 NB

Enschede, The Netherlands

Full list of author information is available at the end of the article
}

oxytocin and tocolytics. However, the relationships between these variables and cervical dilation are scripted.

A positive feedback loop involving oxytocin plays a central role in the progression of first-stage labor. The hypothalamus releases oxytocin into the bloodstream, which is transported to the uterus and stimulates uterine contractions. The contractions result in descent of the fetus. The descending fetal head causes cervical dilation. Cervical stretch receptors send a signal to the hypothalamus via afferent nerves, stimulating additional release of oxytocin, thereby closing the loop. This loop results in progressively intensifying contractions and dilation over time [5].

A database for a number of contraction and dilation profiles could be established and used for scripted training simulation purposes. However, realistic simulation of the interaction between oxytocin concentrations, uterine contractions, fetal descent, and dilation, for a number of patient profiles, and possibly under external influences

(c) The Author(s). 2018 Open Access This article is distributed under the terms of the Creative Commons Attribution 4.0 International License (http://creativecommons.org/licenses/by/4.0/), which permits unrestricted use, distribution, and reproduction in any medium, provided you give appropriate credit to the original author(s) and the source, provide a link to the Creative Commons license, and indicate if changes were made. The Creative Commons Public Domain Dedication waiver (http://creativecommons.org/publicdomain/zero/1.0/) applies to the data made available in this article, unless otherwise stated. 
such as administration of exogenous oxytocin and tocolytics, requires a model-based approach. Such a model would not only increase insight in the interacting processes, but also greatly expand the range of scenarios that can be simulated beyond the relatively simple phenomena that can be characterized in a database.

In this innovation paper, we lay the foundation for such a model by proposing an empirical model that simulates oxytocin concentrations and contraction and dilation profiles. The model should be able to run in real, or accelerated, time and should be easy to manipulate to reflect different patients.

\section{Methods}

Basic assumptions are made, similar to the ones in the article of Bastos et al. [3] and based on understanding of physiological relations, in order to keep the model as simple as possible, while approaching the target data of Zhang et al. [6]. The subsystems and variables connecting them, as described in the introduction, are reflected in the block diagram of Fig. 1.

The model equations referring to Fig. 1 from left to right are introduced below. The rate of oxytocin release by the hypothalamus $r(t)$ in $\mathrm{mU} / \mathrm{min}$ has a fixed component, reflected in the parameter $P_{1}$ and depends linearly via a gain $P_{2}$ on the sensed dilation $d(t)$ in centimeters:

$$
r(t)=P_{1}+P_{2} d(t)
$$

Units of parameters can easily be derived from the units of the variables. The change in mass of oxytocin depends on the elimination rate constant $P_{3}$, the current mass $m(t)$ in $\mathrm{mU}$, and the release rate, represented by a first-order pharmacokinetic model:

$$
\dot{m}(t)=-P_{3} \mathrm{~m}(t)+r(t)
$$

Dividing the mass by the volume of distribution $P_{4}$ results in the concentration of oxytocin in $\mathrm{mU} / \mathrm{mL}$ :

$$
c(t)=\frac{m(t)}{P_{4}}
$$

The concentration dependency of contraction frequency $f(t)$ in $1 / \mathrm{min}$ and contraction amplitude $a(t)$ in $\mathrm{mm} \mathrm{Hg}$ is represented by a sigmoidal curve, Eqs. (4) and (5). For example in Eq. (4), for a concentration equal to zero, the frequency is zero; for a concentration equal to $P_{6}$, it is $50 \%$ of the maximum frequency $P_{5}$; and for higher concentrations, it tends toward $P_{5}$. The slope of both pharmacodynamic relationships is governed by $P_{7}$ :

$$
f(t)=P_{5} \frac{c(t)^{P_{7}}}{P_{6} P_{7}+\mathrm{c}(t)^{P_{7}}}
$$

The amplitude has a non-zero baseline $P_{8}$ and a concentration-dependent part reflected in $P_{9}$ (the difference between the maximum and baseline amplitude values):

$$
a(t)=P_{8}+P_{9} \frac{\mathrm{c}(t)^{P_{7}}}{P_{6} P_{7}+c(t)^{P_{7}}}
$$

The change in dilation depends on the pressure exerted by the fetus on the cervix $P_{10}$, which is assumed fixed in this version of the model, and on the product of frequency and amplitude. This second influence is assumed linearly proportional with gain $P_{11}$. Thus, the resulting uterine model is

$$
\dot{d}(t)=P_{10}+P_{11} \mathrm{f}(t) \mathrm{a}(t)
$$

Referenced and empirically adjusted parameters are listed in Table 1.

Equations (1-6) were implemented in MATLAB (MATLAB R2017a, The MathWorks Inc.) using the Euler forward method with an integration step size of $1 \mathrm{~min}$ to integrate the two differential equations. Model simulation results are presented and compared to target data obtained from Zhang et al. [6] for cervical dilation.

\section{Results}

Figure 2 shows simulation results from the initial conditions $d(0)=2.00 \mathrm{~cm}$, and $m(0)=275 \mathrm{mU}$, using the parameters listed in Table 1. The stars in Fig. 1 correspond to dilation data for patient A in Zhang et al. [6]. This patient was admitted at $2 \mathrm{~cm}$ and labor progressed to $10 \mathrm{~cm}$ with labor considered non-protracted.

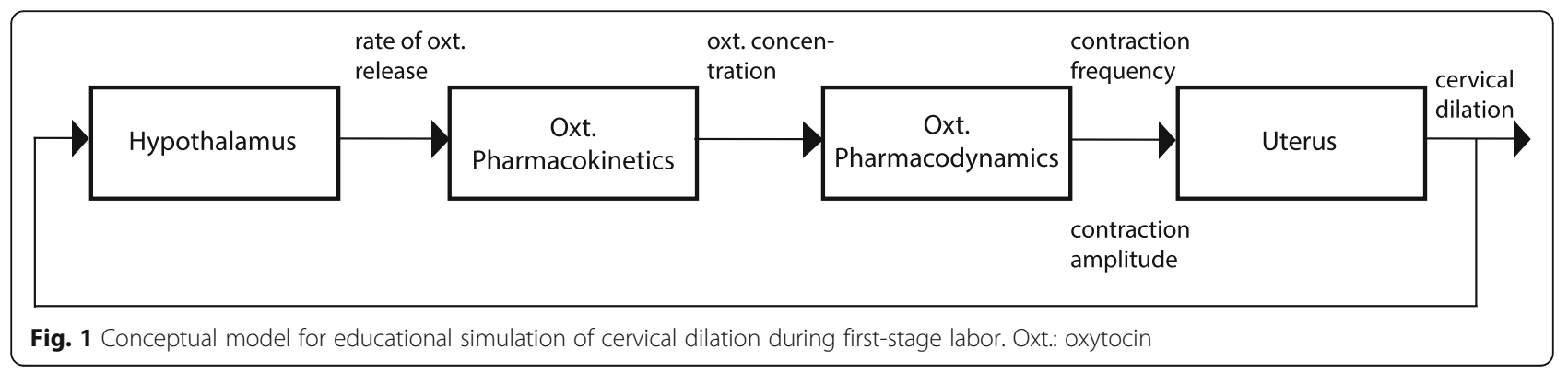


Table 1 Model parameters. For consistency, all values are given in three significant digits

\begin{tabular}{|c|c|c|c|c|}
\hline Symbol & Description & Value & Unit & Reference \\
\hline$P_{1}$ & Baseline oxytocin release rate in hypothalamus & 0.740 & $\mathrm{mU} / \mathrm{min}$ & [7] \\
\hline$P_{2}$ & Gain from cervical dilation to oxytocin release rate in hypothalamus & 50.0 & $\mathrm{mU} /(\min \mathrm{cm})$ & \\
\hline$P_{3}$ & Pharmacokinetic parameter: Elimination rate constant & 0.0693 & $1 / \min$ & [3] \\
\hline $\mathrm{P}_{4}$ & Pharmacokinetic parameter: Volume of distribution & 18,700 & $\mathrm{~mL}$ & {$[8,9]$} \\
\hline$P_{5}$ & Maximal concentration frequency & 0.500 & $1 / \min$ & [2] \\
\hline$P_{6}$ & Pharmacodynamic parameter: Oxytocin concentration resulting in 50\% effect & 7.90 & $\mathrm{mU} / \mathrm{mL}$ & [3] \\
\hline$P_{7}$ & Pharmacodynamic parameter: Slope of sigmoidal curve & 1.11 & dimensionless & [2] \\
\hline$P_{8}$ & Baseline contraction amplitude & 40.0 & $\mathrm{~mm} \mathrm{Hg}$ & [10] \\
\hline$P_{9}$ & Maximal contraction amplitude & 40.0 & $\mathrm{~mm} \mathrm{Hg}$ & [2] \\
\hline$P_{10}$ & Dilation increase due to pressure exerted by the fetus on the cervix & $1.00 \times 10^{-3}$ & $\mathrm{~cm} / \mathrm{min}$ & {$[11]$} \\
\hline$P_{11}$ & Dilation increase due to contraction frequency and amplitude & $1.90 \times 10^{-2}$ & $\mathrm{~cm} / \mathrm{mm} \mathrm{Hg}$ & \\
\hline
\end{tabular}

\section{Discussion}

Simulated dilation matches dilation in a normal patient in an approximation that is considered realistic enough for educational simulation. Parameters $P_{2}$ and $P_{11}$ were adjusted to achieve this match. Further research could address which parameters are patient- or population-specific and can be used to simulate different labor types. The model parameter estimation procedure could then be formalized so that a clinical instructor can easily use it to meet his or her educational objectives. Ongoing work involves expanding the set of target data and matching simulation results to them, to enhance model validity and demonstrate the possibility to match different patient profiles. Critical analysis of the pharmacokinetic model may be necessary. It would also be interesting to explore validity of the model for exogenous oxytocin administration.

\section{Conclusion}

An original empirical model for educational simulation of oxytocin concentrations, uterine contractions, and cervical dilation in first-stage labor is presented. Simulation results for cervical dilation match target data for a normal patient. The proposed model forms a sound, explicit basis for taking into account more independent variables and patient profiles, and thereby considerably expand the range of training scenarios that can be simulated.
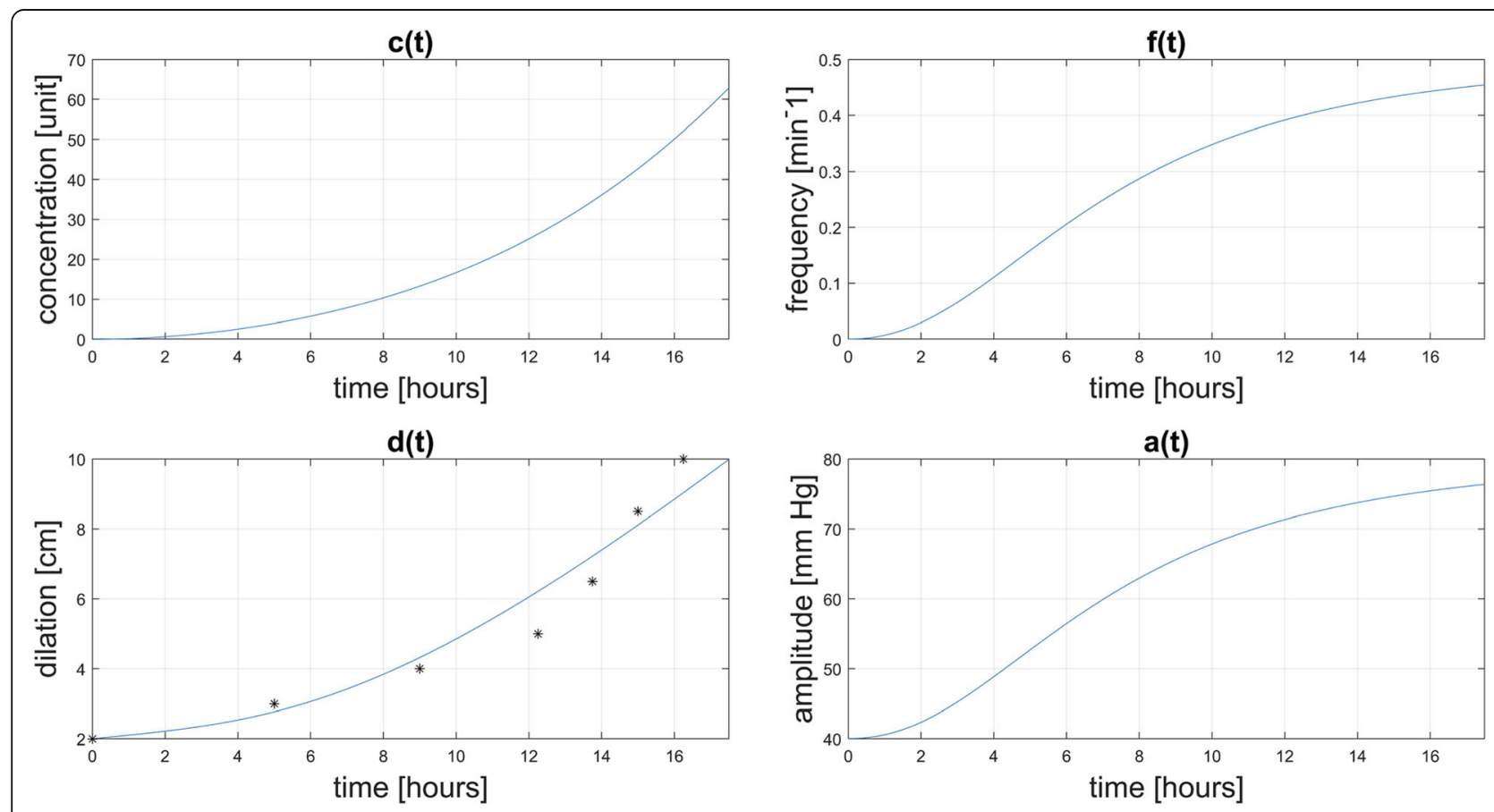

Fig. 2 Simulation results and dilation target data 


\section{Acknowledgements}

Silvano Gefferie won the Nicolaas Westerhof first prize for a young investigator for his presentation of the work elaborated upon in this paper at the conference Applied Modeling in Acute Care, April 20-21, 2017, Enschede, The Netherlands. Part of the salary of Willem van Meurs in the 2016-2017 academic year was funded by a grant from CAE Healthcare, Montreal, Canada.

\section{Availability of data and materials}

The datasets used and/or analyzed during the current study are available from the corresponding author on reasonable request.

\section{Authors' contributions}

SG, AS, and KW did the research and wrote the manuscript. All authors read and approved the final manuscript. $\mathrm{HZ}$ provided general guidance in the first stages of the research and gave his perspective on the mathematical model in later stages. WvM provided guidance throughout the research project and feedback on academic writing and style. LFB clarified the implementation of her published models for simulation of the effect of oxytocin on uterine contractions. MBvdH-vdJ gave general feedback on the physiological, modeling, and educational simulation aspects of the manuscript.

\section{Ethics approval and consent to participate}

Not applicable.

\section{Competing interests}

Drs. Ferreira Bastos and Van Meurs received royalties for licensing of the Childbirth simulator mentioned in the introduction by the University of Porto to CAE Healthcare, Montreal, Canada. In the 2016-2017 academic year, Willem van Meurs was a consultant to and received a grant from CAE Healthcare, Montreal, Canada. The remaining authors declare that they have no competing interests.

\section{Publisher's Note}

Springer Nature remains neutral with regard to jurisdictional claims in published maps and institutional affiliations.

\section{Author details}

${ }^{1}$ Technical Medicine, University of Twente, Drienerlolaan 5, 7522 NB Enschede, The Netherlands. ${ }^{2}$ Animals in Science, Eurogroup for Animals, Hertogstraat 29, 1000 Brussels, Belgium. ${ }^{3}$ Department of Signal Processing Systems, Faculty of Electrical Engineering, Eindhoven University of Technology, PO Box 513, 5600 MB Eindhoven, The Netherlands. ${ }^{4}$ Department of Applied Mathematics, Faculty of Electrical Engineering, Mathematics, and Computer Science, University of Twente, Drienerlolaan 5, 7522 NB Enschede, The Netherlands. ${ }^{5}$ Cardiovascular and Respiratory Physiology Group, Faculty of Science and Technology, University of Twente, Drienerlolaan 5, 7522 NB Enschede, The Netherlands.

Received: 31 January 2018 Accepted: 21 May 2018

Published online: 15 June 2018

\section{References}

1. Bastos LF, Lobo MF, van Meurs WL, Ayres-de-Campos D. An intrauterine pressure generator for educational simulation of labour and delivery. Med Eng Phys. 2010;32:740-5.

2. Bastos LF, van Meurs W, Ayres-de-Campos D. A model for educational simulation of the evolution of uterine contractions during labor. Comput Methods Prog Biomed. 2012;107:242-7.

3. Lobo MF, Bastos LF, van Meurs WL, Ayres-de-Campos D. A model for educational simulation of the effect of oxytocin on uterine contractions. Med Eng Phys. 2013;35:524-31.

4. Childbirth simulator. https://caehealthcare.com/patient-simulation/lucina. Accessed 8 June 2017

5. Marieb EN, Hoehn K. Pregnancy and Human Development. In: Human anatomy and physiology. 10th ed: Pearson Education, Limited; 2015. p. 1116-7.

6. Zhang J, Landy H, Branch D, Burkman R. Contemporary patterns of spontaneous labor with normal neonatal outcomes. Obstet Gynecol. 2013;116:1281-7
7. Fuchs A-R, Romero R, Keefe D, Parra M, Oyarzun E, Behnke E. Oxytocin secretion and human parturition: pulse frequency and duration increase during spontaneous labor in women. Am J Obstet Gynecol. 1991;165:1515-23.

8. Becker KL. Physiology of vasopressin, oxytocin, and thirst. In: Principles and practice of endocrinology and metabolism. 3rd ed: Lippincott Williams and Wilkins; 2001. p. 276-84.

9. Brandis K. Fluid Physiology. http://www.anaesthesiamcq.com/FluidBook/fl2 1.php. Accessed 1 June 2017

10. Caldeyro-Barcia R, Poseiro JJ. Oxytocin and contractility of the pregnant human uterus. Ann N Y Acad Sci. 1959;75(2 The Uterus):813-30.

11. Antonucci MC, Pitman MC, Eid T, Steer PJ, Genevier ES. Simultaneous monitoring of head-to-cervix forces, intrauterine pressure and cervical dilatation during labour. Med Eng Phys. 1997;19:317-26.

\section{Ready to submit your research? Choose BMC and benefit from:}

- fast, convenient online submission

- thorough peer review by experienced researchers in your field

- rapid publication on acceptance

- support for research data, including large and complex data types

- gold Open Access which fosters wider collaboration and increased citations

- maximum visibility for your research: over $100 \mathrm{M}$ website views per year

At BMC, research is always in progress.

Learn more biomedcentral.com/submissions 